\title{
Femina (Trinity College, Cambridge MS B.14.40), edited with an Introduction and Notes by William Rothwell
}

\section{G. Matteo Roccati}

\section{(2) OpenEdition}

Journals

\section{Édition électronique}

URL : http://journals.openedition.org/studifrancesi/9133

DOI : 10.4000/studifrancesi.9133

ISSN : 2421-5856

Éditeur

Rosenberg \& Sellier

\section{Édition imprimée}

Date de publication : 1 juin 2008

Pagination : 165

ISSN : 0039-2944

\section{Référence électronique}

G. Matteo Roccati, «Femina (Trinity College, Cambridge MS B.14.40), edited with an Introduction and Notes by William Rothwell », Studi Francesi [En ligne], 154 (LII | I) | 2008, mis en ligne le 30 novembre 2015, consulté le 10 janvier 2021. URL : http://journals.openedition.org/studifrancesi/9133; DOI : https://doi.org/10.4000/studifrancesi.9133

Ce document a été généré automatiquement le 10 janvier 2021.

\section{cc) (†) $\odot$}

Studi Francesi è distribuita con Licenza Creative Commons Attribuzione - Non commerciale - Non opere derivate 4.0 Internazionale. 


\title{
Femina (Trinity College, Cambridge MS B.14.40), edited with an Introduction and Notes by William Rothwell
}

\author{
G. Matteo Roccati
}

\section{RÉFÉRENCE}

Femina (Trinity College, Cambridge MS B.14.40), edited with an Introduction and Notes by William ROTHWELL, The Anglo-Norman On-Line Hub, 2005 («Texts and Publications»), tirage papier de 118 pages A4.

1 Femina, conservé uniquement dans le manuscrit de Cambridge, est un texte trilingue du début $\mathrm{du} \mathrm{xv}^{\mathrm{e}}$ siècle, rédigé comme moyen d'enseignement du français: Liber iste vocatur femina quia sicut femina docet infantem loqui maternam sic docet iste liber juvenes rethorice loqui gallicum prout infra patebit. Au-delà de l'apprentissage de la langue, les contenus - à la fois pratiques et moraux - révèlent également la volonté de fournir un bref manuel d'éducation. Même s'il se présente comme un tout, il est en fait composé de quatre sections; les trois premières sont tirées d'œuvres antérieures: elles sont constituées d'extraits du Tretiz de Walter of Bibbesworth, de Urbain le Courtois et des Proverbes de bon enseignement de Bozon. Ces extraits sont accompagnés de la traduction en moyen anglais (intercalée toutes les deux lignes dans le manuscrit, imprimée en regard dans l'édition) et de notes de prononciation en latin en bas de page; des rubriques présentant le contenu qui va suivre et quelques brefs passages en latin sont intercalés. À ces trois sections le copiste en a ajouté une quatrième, organisée en trois colonnes, qui reprend le vocabulaire français de la première section en le présentant en ordre approximativement alphabétique et en l'accompagnant de l'indication de la prononciation et de la traduction anglaise. Comme le souligne l'introduction, il s'agit 
donc d'une œuvre originale, non d'une simple compilation, selon l'opinion reçue jusqu'à présent.

2 L'édition est consultable, de manière très aisée, et téléchargeable (donc imprimable) à partir du site www.anglo-norman.net/texts/femina.pdf. L'introduction présente l'œuvre et la méthode d'édition; elle met également en évidence les limites des compétences de l'auteur. Le texte est accompagné d'un riche et précis apparat de notes; des couleurs différentes distinguent les langues (procédé bien plus lisible que le recours à différentes polices). 